\title{
Uma leitura territorial e escalar dos processos inovadores da transição agroecológica em dois municípios do Vale do Paraíba e do Litoral Norte de São Paulo, Brasil
}

\author{
M. John Wojciechowksi \\ Universidade Federal do ABC - São Bernardo do Campo - SP - Brasil \\ ORCID: https://orcid.org/0000-0001-6384-7418 \\ Arilson Favareto \\ Universidade Federal do ABC - São Bernardo do Campo - SP - Brasil \\ ORCID: https://orcid.org/0000-0003-1825-7165 \\ Silvia Moreira Rojo Vega \\ Agência Paulista de Tecnologia dos Agronegócios - Ubatuba - SP - Brasil \\ ORCID: https://orcid.org/0000-0001-6221-1634 \\ Isabel Fernandes Pinto Viegas \\ Agência Paulista de Tecnologia dos Agronegócios - Ubatuba - SP - Brasil \\ ORCID: https://orcid.org/0000-0002-2852-3810
}

\begin{abstract}
Resumo
A aplicação das teorias de transição sociotécnica às práticas dos Sistemas Agroalimentares Alternativos (SAA) tem permitindo aprofundar o entendimento dos processos de inovação desencadeados pela rede de atores durante a transição agroecológica. Contudo estes modelos frequentemente reduzem a escala e o território a repositórios estáticos de ativos e passivos que determinam a escala do nicho agroecológico em relação ao regime alimentar corporativo dominante. Na tentativa de superar a leitura dual e de captar a multidimensionalidade da inovação implícita nos processos de transição agroecológica apresentamos um modelo analítico formulado a partir da articulação conceitual de elementos constitutivos da teoria das configurações territoriais, da construção social de mercados agroecológicos, da governança reflexiva e da escala como ação social estratégica. Aplicamos este modelo à análise das transições agroecológicas em curso em dois municípios do Vale do Paraíba e do Litoral Norte de São Paulo. Evidenciamos que as inovações tecnológicas e a geração de novos conhecimentos no processo de transição são tributárias das habilidades sociais dos atores envolvidos na construção de coalizões sociais amplas e de arenas reflexivas de governança capazes de traduzir os novos conhecimentos socio-técnicos
\end{abstract}


disponíveis em práticas concretas, abrindo assim os espaços de manobra da transição agroecológica com inclusão produtiva da agricultura familiar.

Palavras-chave: Transição agroecológica. Inovação. Coalizões Sociais. Escala.

\section{A territorial and scalar reading of innovative processes of agro-ecological transition in two municipalities in the Paraíba Valley and in the Northern Coast of São Paulo, Brazil \\ Abstract}

The application of transition theories to the study of alternative food networks (AFNs) have improved the understanding of innovation processes triggered by the networks of actors during agro-ecological transitions. However, these models often reduce the categories of scale and territory as repositories of variables that define the dual relationship between the agro-ecological niche and the corporate food regime. In an attempt to overcome the static and dualistic niche-regime relation and, to capture the multidimensionality of innovation processes implicit in the agro-ecological transition pathway, we present an analytical model based on the precepts of: territorial configurations, social construction of agro-ecological markets, reflexive governance and scale as a social strategy. We applied this model to the analysis of agro-ecological transitions in two municipalities in the Paraíba Valley and in the Northern Coast of São Paulo, Brazil. We show that technological innovations and the generation of new knowledge in the transition process are dependant on the social skills of the actors involved in building broad social coalitions and reflexive governance spaces capable of converting knowledge into practices that result in the inclusion of family farmers in the scaling-up of agro-ecological transitions.

Keywords: Agro-ecological Transition. Innovation. Social Coalitions. Scale.

\section{Una lectura territorial y escalar de los procesos innovadores de la transición agroecológica en dos municipios de Vale do Paraíba y de la Costa Norte de São Paulo, Brasil \\ Resumen}

La aplicación de las teorías de transición sociotécnica a las prácticas de los Sistemas Agroalimentarios Alternativos (SAA) han permitido profundizar la comprensión de los procesos de innovación activados por las redes de actores durante la transición agroecológica. Sin embargo, estos modelos a menudo reducen la escala y el territorio a repositorios estáticos de activos y pasivos que determinan la escala del nicho agroecológico en relación con el régimen corporativo dominante. Con el intento por superar la lectura dual y capturar la multi-dimensionalidad de la innovación implícita en el proceso de transición agroecológica, presentamos un modelo analítico formulado a partir de la articulación conceptual de los elementos constitutivos de las configuraciones territoriales, construcción social de mercados agroecológicos, la gobernanza reflexiva y la escala como acción social estratégica. Aplicamos este modelo a la análisis de las transiciones agroecológicas en curso en dos municipios del Valle de Paraíba y de la Costa Norte de São Paulo, Brasil. Mostramos que las innovaciones tecnológicas y la generación de nuevos conocimientos en el proceso de transición están vinculadas a las habilidades sociales de los actores involucrados en la construcción de amplias coaliciones sociales y arenas de gobernanza reflexivas capaces de traducir nuevos conocimientos socio-técnicos en prácticas concretas, abriendo espacios de maniobra de la transición agroecológica con inclusión productiva de la agricultura familiar. Palabras-clave: Transición agroecológica. Innovación. Coaliciones sociales. Escala. 


\section{Introdução'}

As tentativas de transição agroecológica têm gerado durante as últimas duas décadas uma ampla gama de abordagens e experiências no contexto rural. Longe de ser um tema puramente acadêmico, este debate tem sido acompanhado de uma vigorosa militância, organizada em torno de expressões como democracia alimentar, cidadania alimentar e soberania alimentar (RENTING et al., 2014; MARSDEN E SONNINO, 2008). Parece correto afirmar que na literatura acadêmica e normativa dos sistemas agroalimentares alternativos predominam estudos de casos e a escala local de análise. Há ainda certa ênfase para o papel da agricultura familiar, segmento social que ainda se configura como importante ofertante de alimentos agroecológicos no Brasil (NIEDERLE, 2017). Apesar da identificação destes traços relativos a tal campo de estudos, o conceito de transição agroecológica, como recurso analítico, encontrase ainda em construção e não existe definição única e consensual ou modelo a ser seguido (SCHMITT, 2013; BUAINAIN, 2006).

Entre as várias abordagens disponíveis, uma das mais profícuas envolve a aplicação das teorias de transição sociotécnica às práticas dos Sistemas Agroalimentares Alternativos (SAA). Tais leituras têm permitindo aprofundar o entendimento dos processos de inovação desencadeados pelas redes de atores durante a transição agroecológica. Contudo estes modelos frequentemente reduzem a escala e o território a repositórios estáticos de ativos e passivos que determinam a escala do nicho agroecológico em relação ao regime alimentar corporativo dominante.

$\mathrm{Na}$ tentativa de superar a leitura dual nicho-regime e captar a multidimensionalidade da inovação implícita nos processos de transição agroecológica, apresentamos um modelo analítico formulado a partir da articulação conceitual de elementos constitutivos das teorias das configurações territoriais, da construção social de mercados, da governança reflexiva e da escala como ação social estratégica. Este modelo é aplicado à análise das transições agroecológicas em curso em dois municípios do Vale do Paraíba e do Litoral Norte de São Paulo. A hipótese que se pretende demonstrar é que as inovações tecnológicas e a geração de novos conhecimentos no processo de transição são tributárias das habilidades sociais dos atores em moldar coalizões sociais amplas e arenas reflexivas de governança capazes de traduzir os novos conhecimentos socio-técnicos disponíveis em práticas concretas, abrindo assim os espaços de manobra da transição agroecológica com inclusão produtiva da agricultura familiar.

Para apresentar evidências que permitam a verificação desta hipótese, o artigo está organizado em cinco seções. A primeira introduz o tema, o objetivo geral e a forma de abordagem. A segunda apresenta o debate conceitual-analítico sobre a relação entre inovação e transição agroecológica com o objetivo de identificar os avanços e os limites dos modelos disponíveis. A partir desta discussão, a terceira seção detalha o marco analítico anunciado e a metodologia aplicada ao estudo de caso. A quarta seção apresenta os resultados que desvelam a relação entre a formação de coalizões sociais amplas e a gerações de inovações aplicáveis por

${ }^{1}$ Este artigo traz os principais resultados da tese de doutorado do primeiro dos autores, orientada pelo segundo autor, no Programa de Pós Graduação em Planejamento e Gestão do Território da UFABC. A terceira e quarta autoras contribuíram com importantes insumos para a pesquisa de campo. 
agricultores familiares nos processos de transição agroecológica nos municípios de Cunha (Vale do Paraíba-SP) e Ubatuba (Litoral Norte-SP). A quinta e última seção conclui o texto com destaque à articulação analítica dos conceitos de território, escala e governança para captar e identificar as inovações geradas no processo de transição.

\section{As teorias da transição sociotécnica e da transição agroecológica}

O que diferencia as leituras da transição agroecológica é seu caráter analítico mais restrito (ou setorial) ou multidimensional. No primeiro caso, os estudos têm como foco a aplicação de princípios ecológicos ao manejo dos agroecossistemas em contextos socioambientais específicos (EMBRAPA, 2006; GLIESSMAN, 2007). Aqui, as análises se concentram na escala da produção e do produtor. Já as perspectivas mais amplas visam integrar o entendimento da relação cíclica entre a agência dos atores e as estruturas institucionais e territoriais. Desta relação podem nascer, em diversas escalas, elementos propulsores ou inibidores do processo de transição (SCHMITT, 2013).

Outros autores buscam inspiração nas teorias de transição para captar a complexidade e multidimensionalidade dos processos de inovação e gestão de conhecimentos da transição agroecológica (PLOEG; WISKERKE, 2004). Fundamentados nos trabalhos referenciais de Geels (2002), os modelos da Perspectiva Multinível (PMN) sustentem que a inovação dependeria da tutela do nicho perante o antagonismo do regime alimentar dominante. $\mathrm{O}$ nicho ganharia escala num movimento ascendente, de baixo para cima. A virada do regime - objetivo fim da difusão e expansão do nicho -, seja pela integração do mesmo ao regime, ou mesmo pela substituição de práticas, dependeria, de um lado, do desgaste do regime em voga, abrindo janelas de oportunidade e, do outro, da capacidade do nicho de preencher estas janelas com novas propostas de hábitos, práticas de consumo, valores, aspectos engrenados às dinâmicas das inovações sociotécnicas (BRUNORI et al., 2011).

Embora o valor destes modelos esteja na sua capacidade de evidenciar as tensões da inovação sociotécnica em relação à possibilidade de traduzi-las em algo capaz de levar a transformações mais amplas, sua aplicação não está isenta de críticas.

A primeira tem a ver com a unilateralidade da escala local, onde a inovação sempre é atrelada ao nicho (escala micro), em um movimento de baixo para cima. A superação desta escala confirmar-se-ia com o aumento ou difusão da produção agroecológica. Enquanto isso, diversos autores sugerem que a escala deve ser entendida como um processo de construção social e não como uma definição ex-ante (SWYNGEDOUW, 2004; BROWN; PURCELL, 2004; HINRICH, 2003). Seguindo as orientações de Brown e Purcell (2004) e também de Hinrich (2003) este entendimento de escala é necessário para evitar a chamada "armadilha escalar" onde se associa à escala local (ou qualquer outra escala) um determinado resultado inerente.

A segunda diz respeito à separação artificial entre paisagem sociotécnica (escala macro, segundo o modelo desta perspectiva) e o contexto onde o nicho desenvolve as inovações. Como o próprio termo indica, a transição agroecológica 
sugere uma aproximação simbiótica entre as estruturas técnico-sociais e os sistemas ecológicos. E o lócus por excelência desta "paisagem” é o território. Mas a noção de território é muito mais do que um repositório estático de fatores propulsores (ativos) ou inibidores (passivos), sejam eles ecológicos, culturais, socais, econômicos ou institucionais. Territórios têm uma estrutura e uma dinâmica. Nos termos de Favareto et al. (2015), um território é uma unidade na qual está em questão justamente a disputa por recursos e seus usos, e que convida a superar três dicotomias: entre fatores locais e extralocais, entre sistemas sociais e os sistemas naturais de que dependem, e entre processos tradicionalmente associados ao rural ou ao urbano. Por isso é necessário aplicar uma abordagem analítica do território, que não só identifique as estruturas e normas sociais que constrangem ou ampliam a transição, mas também como ele se traduz num campo de possíveis para a constituição das trajetórias sociais dos atores envolvidos com os processos de transição. Pode soar evidente esta afirmação, mas a compreensão de que o território é ao mesmo tempo estruturado e estruturante do processo de desenvolvimento é razoavelmente recente (FAVARETO, 2007). Dinâmicas de desenvolvimento de um território precisam ser entendidas, assim, como um processo histórico relacional (porque apoiado num conjunto de interdependências), multidimensional (porque estas interdependências se dão entre domínios tradicionalmente apartados em análises e modelos teóricos disciplinares), e multiescalar (porque embora o território implique necessariamente em dar ênfase aos aspectos endógenos, não se trata de uma unidade autônoma, e sim da síntese de determinações com origem em várias escalas geográficas).

Finalmente, a terceira ressalva diz respeito à primazia unilateral do mercado na formação de inovações sociotécnicas, mesmo quando este deve lidar com as múltiplas dimensões da paisagem sociotécnica (institucional, cultural, ecológica). No caso específico da transição agroecológica, esta trama complexa se evidencia de forma privilegiada na formação (ou na ausência) de processos e estruturas da governança reflexiva - elemento central de sustentação da transição - com a participação de diferentes atores envolvidos, como agricultores, formuladores de políticas e pesquisadores (MARSDEN, 2012; 2013; 2016; SONNINO; MARSDEN, 2006; HORLGINS; MARSDEN, 2011; SONNINO et al., 2011). Considerando a relação direta entre a geração de novos conhecimentos e inovação em prol da transição agroecológica, tem crescido o reconhecimento da necessidade de criar ou conectar espaços e estruturas reflexivas de governança reorientando a interação entre os agentes economicos, sociais e institucionais no sentido desejado para estes processos de mudança.

\section{Marco Analítico}

A articulação conceitual dos elementos constitutivos da construção social de mercados agroecológicos (NIEDERLE, 2017), da governança que interage com diversos graus de reflexividade (KOOIMAN, 2003), da escala como ação social estratégica (SWYNGEDOUW, 2004) e das configurações territoriais como fator compreensivo das trajetórias dos agentes (FAVARETO et al., 2015), permite a construção da matriz analítica para interpretar as possibilidades e limites da transição agroecológica. Tal matriz analítica busca: 1) superar o desafio de reduzir a noção de escala a uma leitura produtivista; 2) reposicionar a escala como a soma de 
estratégias que buscam ampliar o alcance da transição para além da questão setorial e incorporar seu enraizamento territorial efetivo; 3) dar ênfase ao papel das coalizões sociais na construção de inovações em prol da transição, de forma territorialmente situada; e 4) qualificar a reflexividade dos espaços de governança em termos de três ordens: ações, normas e valores.

A matriz cruza oito categorias estruturantes da transição agroecológica, agrupadas em quatro eixos (Quadro 1), com os três graus da governança conforme Kooiman (2003). De acordo com estes autores a "primeira ordem" se refere à rotina, às soluções técnicas para os problemas do dia-a-dia e é normalmente realizada como cumprimento de um acordo pré-determinado entre as partes. A segunda ordem busca entender quais são os constrangimentos da transição postos pela configuração territorial, identifica as habilidades cognitivas e dialógicas necessárias para superar os entraves e estabelece as normas e regras necessárias para dar a estabilidade exigida para que possam ser desenvolvidas e colocadas em prática. Essencialmente, a terceira ordem norteia a construção de institucionalidades (segunda ordem) e define como as regras e regulamentos serão implementados (primeira ordem). É preciso mencionar que nesta concepção de governança os autores ressaltam a importância do papel dos modelos mentais e estruturas cognitivas dos agentes sociais que podem reforçar ou dificultar a formação de processos de cooperação em prol da transição.

Quadro 1: Eixos e categorias da matriz analítica

\begin{tabular}{|c|c|}
\hline $\begin{array}{c}\text { Eixos da matriz } \\
\text { analítica }\end{array}$ & Descrição das oito categorias \\
\hline Coordenação & $\begin{array}{l}\text { 1) Relação rural-urbana: ações, normas e valores que } \\
\text { superam a tradicional compartimentalização urbano-rural } \\
\text { com o objetivo de valorizar e visibilizar o trabalho dos } \\
\text { produtores, encurtar relações entre produtores e } \\
\text { consumidores, e romper com o isolamento social. } \\
\text { 2) Qualidade e certificação: Ações, normas e valores } \\
\text { voltados para garantir conformidade com padrões de } \\
\text { qualidade e certificação dos alimentos agroecológicos } \\
\text { reforçando a salubridade dos alimentos e a dinâmica } \\
\text { relacional da confiança entre produtores e consumidores. }\end{array}$ \\
\hline Contratualização & $\begin{array}{l}\text { 3) Coalizões intersetoriais: essa categoria visa captar a } \\
\text { formação de coalizões amplas, para além da setorialidade } \\
\text { formando a base de apoio ao projeto territorial de } \\
\text { transição agroecológica. } \\
\text { 4) Coalizões intrasetoriais: reconhece a importância da } \\
\text { formação de coalizões de interesses, para dentro do setor } \\
\text { e, portanto, busca captar o adensamento de estratégias } \\
\text { de cooperação (político, social, inclusivo, econômico etc). }\end{array}$ \\
\hline Territorialização & $\begin{array}{l}\text { Inclusão produtiva: Ações, normas e valores voltados para } \\
\text { a construção de redes solidárias valorizando as diversas } \\
\text { manifestações da agricultura familiar (caipiras, caiçaras, } \\
\text { quilombos, indígenas, etc) tornando este ator central nas }\end{array}$ \\
\hline
\end{tabular}




\begin{tabular}{|l|l|l|}
\hline & $\begin{array}{l}\text { relações entre entre produtor e consumidor da } \\
\text { agroecologia. } \\
\text { 6) }\end{array}$ & $\begin{array}{l}\text { Consumo inclusivo: Prática, normas e valores que } \\
\text { reforçam a formulação de preços justos e distribuição } \\
\text { socioespacial mais igualitária para democratizar o acesso } \\
\text { apo alimento saudável. }\end{array}$ \\
\hline institucional & 7) $\begin{array}{l}\text { Extensão Rural: focada no agente da extensão rural e no } \\
\text { seu ambiente institucional, viabilizando a construção } \\
\text { social das inovações (ou não), integrando o conhecimento } \\
\text { técnico com os saberes e valores locais e tradicionais. } \\
\text { Neste aspecto, a inovação, uso e adaptabilidade de } \\
\text { tecnologias sociais é indicador importante da virada de } \\
\text { qualidade da extensão rural. } \\
\text { Espaços de participação social: refere-se aos espaços de } \\
\text { participação social, abertos à construção coletiva. Estes } \\
\text { espaços podem ser institucionais e permanentes, mas não } \\
\text { necessariamente de apresentam desta forma. }\end{array}$ \\
\hline
\end{tabular}

As oito categorias de construção social da transição agroecológica cruzadas com os três graus de reflexividade geram 24 elementos qualitativos para analisar a capacidade de escalonamento da transição agroecológica. Ainda, para poder comparar as experiências de transição agroecológica foi atribuído, aos 24 elementos, um sistema de pesos, no qual cada ordem de reflexividade tem o dobro do peso da ordem anterior $(1,2,4)$, reconhecendo a centralidade dos processos reflexivos para a escala da transição e não o contrário, evitando assim a chamada armadilha escalar. A soma desta pontuação gera o valor máximo dos quatro eixos (um para cada componente) e será usado para desenhar o diagrama de radar, expressão gráfica utilizada para facilitar a comparação da escala da transição agroecológica nos casos analisados.

A aplicação desta matriz analítica se deu por meio de um estudo de caso comparativo da transição agroecológica nos municípios de Ubatuba e Cunha. Os dois municípios começaram a sua transição agroecológica nos meados da década de 2000 e hoje apresentam graus diferentes de escala. A escolha de encaminhar a transição agroecológica por meio de Organizações de Controle Social(OCS), compartilhada por estes dois municípios, é fator determinante que permite a comparação. Para chegar às análises aqui realizadas ${ }^{2}$, trabalhamos com informações de documentos e materiais das redes estudadas, além de observação em campo e entrevistas semiestruturadas com produtores agroecológicos, extensionistas e agentes da administração pública local.

\section{Transições agroecológicas na Região do Vale do Paraíba e Litoral Norte - SP}

Atualmente a região do Vale do Paraíba e Litoral Norte, ocupa uma área de 1.626.800 hectares, perfazendo 6,54\% da área do Estado de São Paulo e é formada

${ }^{2}$ A descrição mais detalhada da metodologia aplicada ao estudo está disponível na Tese de Doutorado do primeiro autor deste artigo (WOJCIECHOWSKI, 2019). 
por trinta e nove municípios. Segundo os dados da EMPLASA (2012), a região possui uma população de aproximadamente 2,3 milhões de habitantes e, desde 2012, é reconhecida como Região Metropolitana, conforme Lei Estadual 1.166/12. A partir desta nova institucionalidade, a região foi dividida em cinco sub-regiões administrativas (Figura 1).

Verifica-se atualmente que a região do Vale do Paraíba e Litoral Norte possui significativo desenvolvimento e diversificação produtiva, representando, em 2010, $5,1 \%$ do PIB estadual. A sua localização geográfica é estratégica, visto que, na sua parte alta (sub-regiões 1 a 4, no mapa a seguir), o Vale é ponto de interligação entre duas grandes metrópoles: Rio de Janeiro e São Paulo, sendo cortado por uma das mais importantes rodovias federais, a Presidente Dutra. Em contraste com o Vale do Paraíba, os principais fatores propulsores do Litoral Norte, na parte baixa desta região (sub-região 5, no mapa a seguir), são: o turismo, o dinamismo no setor mobiliário e os grandes projetos no setor petroquímico (CBH-LN, 2017).

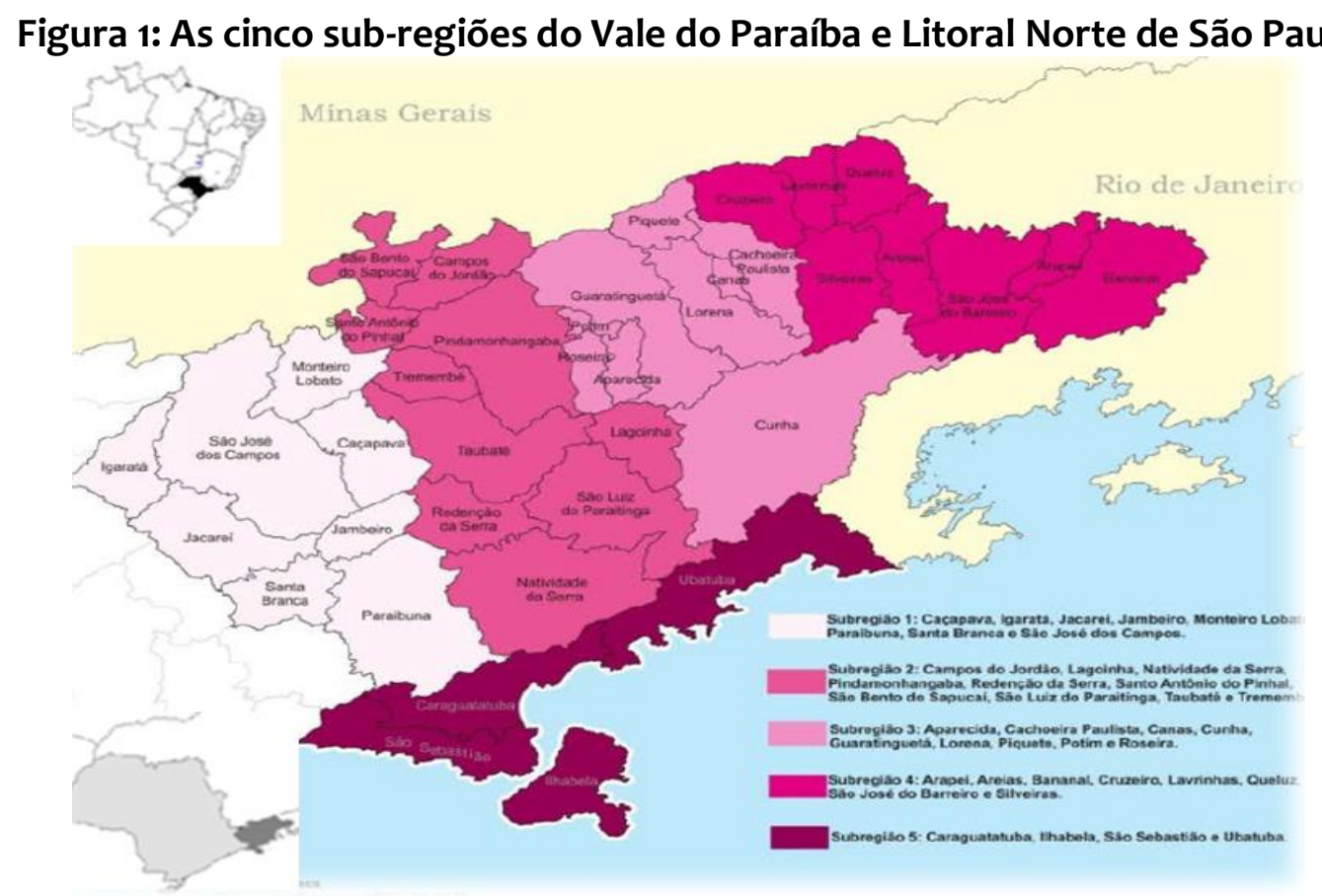

Fonte: (EMPLASA, 2012, 19)

A utilização do solo rural na região do Vale do Paraíba e Litoral Norte é bastante diversificada e corresponde, em grande parte, às suas características naturais como relevo, $\mathrm{pH}$, regimes pluviométricos, declividade. Conta também a definição de áreas de proteção ambiental definidas por Lei - estão ali as maiores áreas de protegidas do Estado de São Paulo, juntamente com o Vale do Ribeira, mais ao sul. O Parque Estadual da Serra do Mar (1977), corre paralelo à linha costeira, e o Parque Nacional da Serra da Bocaina (1971), compartilhado com o Estado do Rio de Janeiro, se situa no limite dos dois estados, fazendo a ligação da Serra do Mar com a Serra da Mantiqueira. No total a Região do Vale do Paraíba e Litoral Norte possui mais de 37\% do seu território protegido por 24 Unidades de Conservação, perfazendo um total de aproximadamente $5.805 \mathrm{~km} 2$. As unidades de conservação nos municípios litorâneos são marcadas por comunidades tradicionais de quilombos, indígenas, caiçaras e pescadores artesanais. 
Conforme o Relatório do PIB dos Municípios Paulistas (SEADE, 2012), a agropecuária apresentou queda na participação do PIB da região como todo: entre 2002 e 2014 a participação no valor agregado caiu de 0,9\% para 0,5\%. Conforme os dados preliminares do Censo Agropecuário de 2017, o Município de Cunha tem o maior número de estabelecimentos rurais (2288) do Vale do Paraíba, dos quais $77 \%$ são de agricultura familiar. Em contraste, os municípios litorâneos têm a menor concentração de unidades produtivas agrícolas. Os resultados preliminares do Censo Agropecuário de 2017 mostram que o Município de Ubatuba conta com 51,5\% (127) de todos os estabelecimentos rurais entre os municípios litorâneos. Destes, quase $93 \%$ está abaixo de 4 módulos fiscais.

Tabela 1 - Tabela Comparativa dos Estudos de Caso e variáveis determinantes

\begin{tabular}{|c|c|c|c|}
\hline DIM & ENSÕES CHAVE E INDICADORES & Cunha & Ubatuba \\
\hline \multirow{7}{*}{ 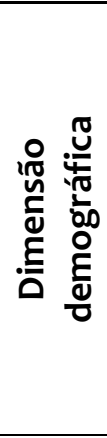 } & População - 2018 & 21.684 & 87.887 \\
\hline & $\begin{array}{l}\text { Taxa de Crescimento pop. \% } \\
(2010-2018)\end{array}$ & $-0,11$ & 1,24 \\
\hline & Densidade Pop. Hab/km2 - 2018 & 15,41 & 124,11 \\
\hline & Grau de Urbanização - 2018 & $62 \%$ & 97,66 \\
\hline & $\begin{array}{c}\text { Taxa de Crescimento pop. (Rural) } \\
\text { e (Urbana)\% (2010-2018) }\end{array}$ & $(-1,82)(1,12)$ & $(0,93)(1,24)$ \\
\hline & $\operatorname{IDH}(2010)$ & 0,68 & 0,75 \\
\hline & Índice de Gini (2003) & 0,4 & 0,44 \\
\hline \multirow{7}{*}{ 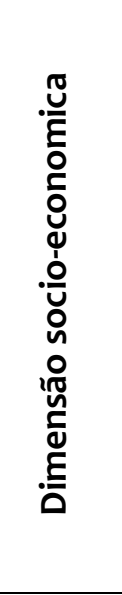 } & PIB per capita - 2016 & $9.847,01$ & $20.447,30$ \\
\hline & Distribuição do PIB do Valor & $\nabla$ 12,9\% (Agro.) & 1,1\% (Agro) \\
\hline & Adicionado (em \%) - comparação & $\nabla \quad 4,4 \%$ (Ind.) & $15 \%$ (Ind.) \\
\hline & $2002-2014$ & $\triangle 74,7 \%$ (Serv.) & $\nabla 83,9 \%$ (Serv.) \\
\hline & $\begin{array}{c}\text { \% da população com rendimento } \\
\text { nominal mensal/capita de até } 1 / 2 \\
\text { salário mínimo [2010] }\end{array}$ & $41,10 \%$ & $34,20 \%$ \\
\hline & $\begin{array}{l}\text { Estrutura Fundiária Rural e } \\
\text { diversificação produtiva }\end{array}$ & $\begin{array}{l}\text { Desconcentração - } \\
\text { Atividade Agrícola } \\
\text { e Agro-turismo }\end{array}$ & $\begin{array}{l}82 \% \text { do território sob } \\
\text { proteção ambiental. } \\
\text { Turismo balneário. }\end{array}$ \\
\hline & $\begin{array}{c}\text { Projetos Seletivo-espacial do } \\
\text { estado }\end{array}$ & Turismo Rural & Boom imobiliário \\
\hline \multirow{3}{*}{ 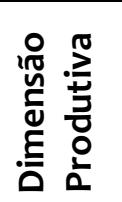 } & Estabelecimentos Rurais 2006 & 2.581 & 142 \\
\hline & Estabelecimentos Rurais 2017 & $2.288(-11,3 \%)$ & $127(-10,5 \%)$ \\
\hline & Número de Unidades OCS (2017) & 14 & 20 \\
\hline
\end{tabular}

Fonte: IBGE-Cidades, 2016; Censo agropecuário, 2017 (Parcial); SEADE, 2018.

Conforme os dados do Cadastro Nacional de Produtores Orgânicos, de maio de 2019, emitido pelo Ministério de Agricultura, Pecuária e Abastecimento (MAPA), na RVPLN existem, atualmente, 143 produtores certificados por auditora e em conformidade com as regras de organizações de controle social (OCS), representando um aumento de 18\% em comparação com os dados de 2017. 71 deles estão agrupados em 10 (OCS) espalhados em 7 municípios da região. Os outros 72 são 
certificados por auditoria (ECOCERT e IBD) ${ }^{3}$. É importante notar que a distribuição espacial segue um padrão bastante definido com forte concentração dos produtores certificados CERT nas planícies do Rio Paraíba do Sul e nos altiplanos da Serra da Mantiqueira, encostando na divisa com o Estado de Minas Gerais. Enquanto os produtores certificados OCS estão na sua maioria concentrados no litoral e nos municípios de transição com as unidades de conservação.

Figura 2: Distribuição espacial dos produtores certificados por auditória na RVPLN: 2017- 2019
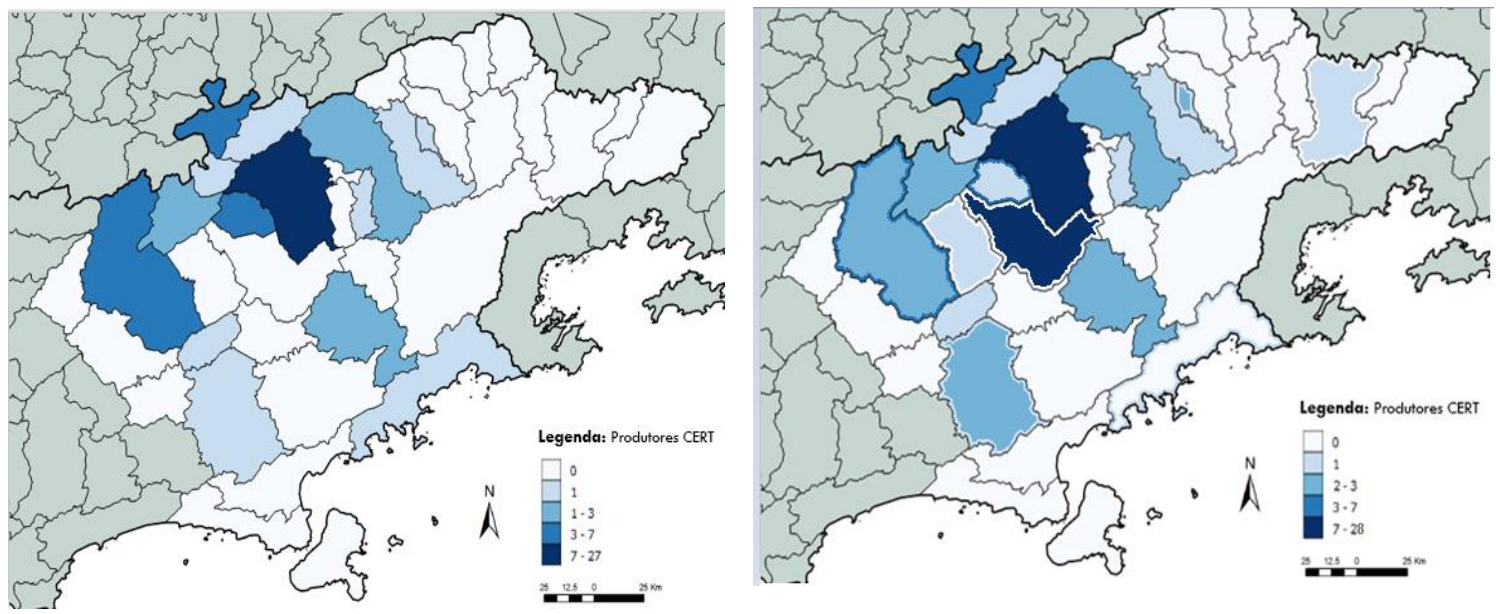

Fonte: Cadastro Nacional de Produção Orgânica MAPA4.

Em contraste com a distribuição espacial dos produtores certificados por auditoria que, quase na sua totalidade está concentrada perto dos principais centros urbanos no Vale do Paraíba, os produtores das organizações de controle social (OCS) podem ser agrupados em dois clusters em municípios de menor porte populacional. O primeiro agrupamento, composto pelos municípios de Cunha, Redenção da Serra, e São Luís do Paraitinga, tendo respectivamente 11, 13 e 14 produtores com designação OCS, representa $47 \%$ dos produtores em conformidade com esta modalidade, e $24 \%$ de todos os produtores agroecológicos no território. O segundo cluster de produtores organizados em OCS está situado nos municípios de Ubatuba e Caraguatatuba, com 20 e 10 produtores respectivamente, representando $42 \%$ dos produtores pertencentes a esta categoria.

3 Os dados referentes à produção e às unidades certificadas por auditoria não foram liberados pelas certificadoras e não são disponibilizados pelos órgãos públicos para a região. Nos municípios estudados não há unidades certificados por auditoria.

4 O cadastro pode ser acessado em: http://www.agricultura.gov.br/ 
Figura 3: Distribuição espacial dos produtores em conformidade com OCS na RVPLN: 2017- 2019
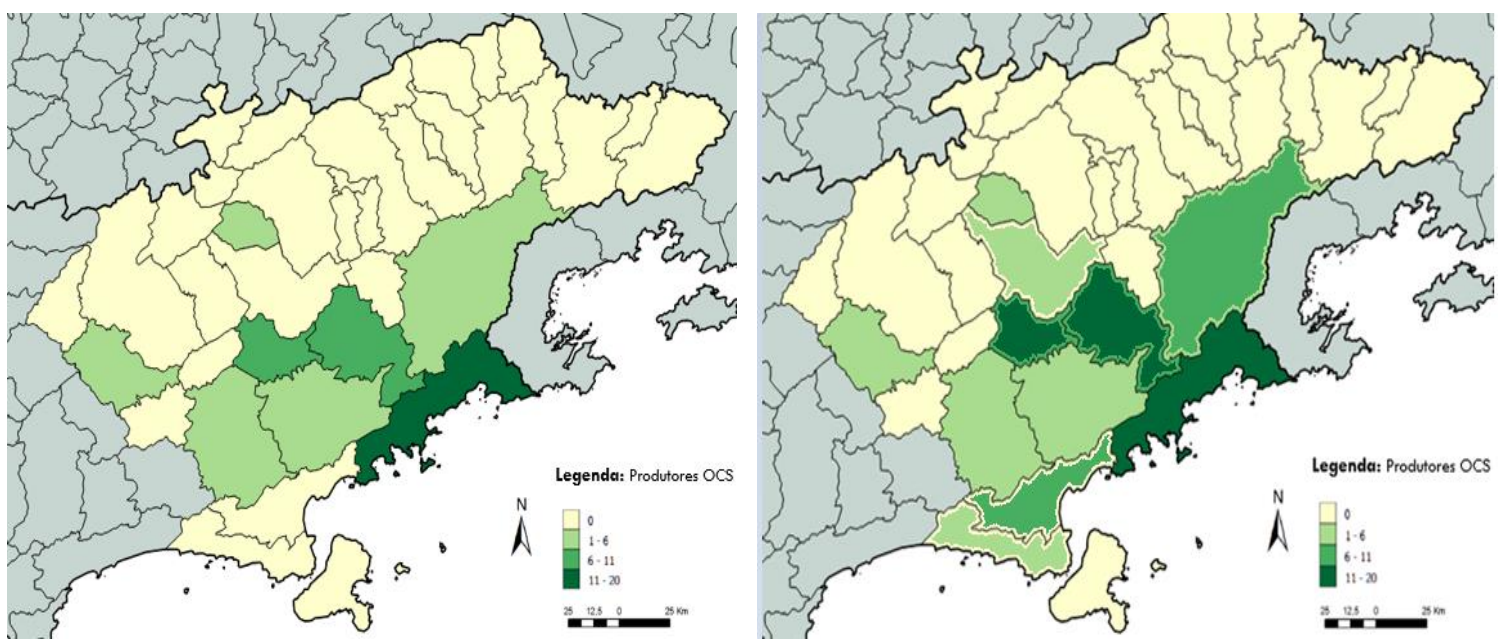

Fonte: Cadastro Nacional de Produção Orgânica.

\section{Análise comparada da transição em dois munícipios da RVPLN}

A trajetória de transição agroecológica em Ubatuba tem como seu marco zero o ano de 2001, com o Plano Setorial de Desenvolvimento Rural e Pesqueiro, elaborado com a participação de agricultores, representantes da sociedade civil organizada e instituições atuantes no apoio ao setor agrícola do município, dentro de um processo mais amplo de elaboração do Plano Diretor Participativo de Ubatuba. A estratégia de elaboração do Plano Setorial como anexo ao Plano Diretor Participativo Municipal foi construída durante dois anos pelo Conselho Municipal de Desenvolvimento Rural e Pesqueiro de Ubatuba (CMDRP). O Conselho foi instaurado no município em 1999 e foi ampliado em 2001, de forma a incluir a representação Regional da Agência Paulista de Tecnologia do Agronegócio (APTA), pelo lado governamental, e representação das populações tradicionais indígenas e quilombolas pelo lado da sociedade civil.

\section{Quadro 4 - Transição agroecológica nos dois municípios - evolução e estruturas de} governança

\begin{tabular}{|c|c|c|c|}
\hline & DIMFNSÕFS CHAVF & Cunha & Uhatuba \\
\hline \multirow{4}{*}{ 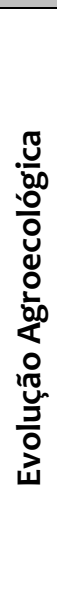 } & $\begin{array}{l}\text { Marco zero da } \\
\text { transição }\end{array}$ & $\begin{array}{l}2006 \text { - Projeto “Viver na Mata } \\
\text { Atlântica” - Serra Acima } \\
\text { 2007/2008 - Grupo de Agricultores } \\
\text { Familiares Agroecológicos (GAFAC) }\end{array}$ & $\begin{array}{l}2001 \text { - Plano Setorial Municipal } \\
2008 \text { - APTA. Estudo de } \\
\text { Unidades Demonstrativas }\end{array}$ \\
\hline & $\begin{array}{l}\text { Força motriz da } \\
\text { Transição }\end{array}$ & $\begin{array}{l}2013 \text { - Sec. Estadual da } \\
\text { Agricultura/CATI - Programa } \\
\text { Microbacias II; acesso ao mercado }\end{array}$ & $\begin{array}{l}\text { Articulação Publica de natureza } \\
\text { mista (Municipal, Estatal e } \\
\text { Conselho Municipal) }\end{array}$ \\
\hline & $\begin{array}{l}\text { Ano de formação do } \\
\text { OCS }\end{array}$ & $\begin{array}{l}2011-\text { APAC } \\
2016 \text { - BioCunha }\end{array}$ & $\begin{array}{l}2009 \text { - OCS Ubatumirim } \\
2013 \text {-OCS Agroecologia Ubatuba } \\
2016 \text { - OCS Ubatuba } \\
\text { Agroecologia }\end{array}$ \\
\hline & $\begin{array}{l}\text { Principal canal de } \\
\text { vendas }\end{array}$ & $\begin{array}{l}\text { Feira local, CSA, disque-roça, } \\
\text { entrega direta }\end{array}$ & $\begin{array}{l}\text { Rede Agroecologica Caiçara, } \\
\text { Feira "Espaço Saudável”, Grupo } \\
\text { Virtual WhatsApp }\end{array}$ \\
\hline
\end{tabular}


(conclusão)

\begin{tabular}{|c|c|c|c|}
\hline & DIMENSÕES CHAVE & Cunha & Ubatuba \\
\hline \multirow{4}{*}{ 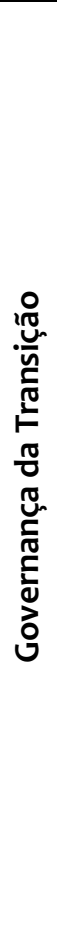 } & $\begin{array}{l}\text { Envolvimento em } \\
\text { Redes }\end{array}$ & Feira Semente Crioula. & $\begin{array}{l}\text { Participação em outras feiras da } \\
\text { cidade (ex: Feira Solidária da } \\
\text { Praça) }\end{array}$ \\
\hline & $\begin{array}{l}\text { Fonte de apoio e } \\
\text { financiamento } \\
\text { recebido }\end{array}$ & $\begin{array}{l}\text { Fundo Petrobras. } \\
\text { Programa Estadual Microbacias II } \\
\text { PDA/MMA }\end{array}$ & $\begin{array}{l}\text { Fundo Petrobras. } \\
\text { Programa Estadual Microbacias } \\
\text { II. } \\
\text { Fundos de Pesquisa. } \\
\text { PDA/MMA }\end{array}$ \\
\hline & $\begin{array}{l}\text { Fatores } \\
\text { determinantes do } \\
\text { modelo de } \\
\text { governança }\end{array}$ & $\begin{array}{l}\text { Trabalho de base, modelos de } \\
\text { extensão. }\end{array}$ & $\begin{array}{l}\text { Inovação tecnológica social (ex: } \\
\text { Estufa ubatubana), Carta de } \\
\text { Princípios, Plano Diretor } \\
\text { Municipal. }\end{array}$ \\
\hline & $\begin{array}{l}\text { Incidência política } \\
\text { sobre o } \\
\text { desenvolvimento } \\
\text { sustentável no } \\
\text { território. }\end{array}$ & $\begin{array}{l}\text { Forte histórico de atuação com } \\
\text { PNAE. } \\
\text { Conflitos entre OCS fragmentam o } \\
\text { movimento perante os atores } \\
\text { institucionais. }\end{array}$ & $\begin{array}{l}\text { O PNAE era um "ponto de } \\
\text { encontro" entre as } \\
\text { institucionalidades formais e } \\
\text { membros produtores da rede. } \\
\text { Atualmente a desarticulação com } \\
\text { o Conselho Municipal de } \\
\text { Desenvolvimento Rural } \\
\text { enfraquece a capacidade de } \\
\text { incidência. }\end{array}$ \\
\hline
\end{tabular}

Esta ampliação foi vista como estratégica para poder alinhar melhor a atuação do Conselho em sintonia com os programas de pesquisa da APTA, com a extensão rural da Coordenadoria de Assistência Técnica Integral (CATI) - ambas sob comando da Secretaria de Agricultura e Abastecimento - e com as necessidades das diversas categorias de agricultores familiares no território. Neste período, a Secretaria Municipal de Agricultura, Pesca e Abastecimento (SMAPA) apoiou a realização do Planejamento Estratégico para o Desenvolvimento Rural Sustentável de Ubatuba por meio do CMDRP, em conjunto com diversas instituições (CATI, APTA, Embrapa, Instituto Florestal, Prefeitura, UNITAU, USP). Este planejamento era o precursor do Plano Setorial e já apontava a necessidade de expandir a rede de serviços de extensão rural para as comunidades tradicionais, apoiar a comercialização local de produtos tradicionais e capacitar os produtores em técnicas de manejo agroecológico.

Deste ambiente favorável surgiram dois projetos de extensão rural estruturantes para a transição agroecológica. O primeiro, datado de 2001 a 2004, era voltado especificamente para a agricultura familiar, com financiamento do Ministério do Desenvolvimento Agrário. O segundo, com recursos do FINEP-Infraestrutura, foi desenvolvido na comunidade tradicional do Sertão de Ubatumirim refletindo os conflitos já existentes entre a gestão do Parque Estadual e as comunidades locais.

Em 2006 a Secretaria realizou a $1^{\text {a }}$ Conferência Municipal de Planejamento dos Setores da Pesca Agricultura e Abastecimento. A conferência gerou os subsídios para o Plano Diretor Participativo de Ubatuba, também aprovado em 2006. As diretrizes da agricultura agroecológica foram traçadas no parágrafo 3 do referido Plano e em grande parte espelhavam as aprendizagens adquiridas até então por meio dos dois projetos de extensão desenvolvidos no município: 
I. Promover e estimular o desenvolvimento de cursos e capacitações incentivando a formação de agentes multiplicadores em técnicas de produção sustentável; II. Garantir o processo de certificação da produção orgânica municipal e estimular a regularização em grupo com participação comunitária (certificação participativa); III. Incentivar a promover a implementação da agricultura orgânica no município; IV Apoiar e orientar sobre legislação ambiental e mediar o diálogo entre agricultores e órgão do meio ambiente; $\mathrm{V}$. Promover o zoneamento agrícola e garantir sua classificação (áreas agrícolas); VII. Garantir o estabelecimento de uma Zona Especial de Desenvolvimento agrícola. (UBATUBA, 2006, 7-8)

Um ano antes da promulgação do referido Plano, em 2005, a SMAPA lançaria a primeira edição da Semana da Agricultura Orgânica. Em 2008 o evento foi instituído pela Lei $n^{\circ} 3123$ com o objetivo de difundir a importância da agricultura orgânica, fortalecer as feiras de alimentos agroecológicos, instaurar o dia de campo e o fórum de discussão, estimular a rede de produção, o comércio dos produtos orgânicos e a agricultura familiar do município. Um ano depois, em 2009, a Unidade de Pesquisa e Desenvolvimento da APTA/UPD, localizada em Ubatuba implementaria, com financiamento da CNPq, um projeto de propriedades de referência da agricultura familiar em transição agroecológica. Deste projeto participaram 25 famílias espalhadas na região sul e norte do município, abrangendo propriedades de três categorias representativas de agricultores familiares de Ubatuba. O primeiro grupo era formado por caiçaras e quilombolas dedicados a reproduzir sistemas de produção tradicionais, com algumas inovações de práticas agroecológicas, mas que estavam limitados pelas restrições ambientais. Com exceção das bananas e mandioca comercializadas em maior escala, estes agricultores se dedicam até hoje às culturas para autoconsumo e para vendas diretas. Este grupo social tinha menor escolaridade e menos equipamentos para cultivar a terra. Estes agricultores foram escolhidos nas comunidades de Ubatumirim (caiçara) e Fazenda da Caixa (quilombo) (MARCHIORI et al., 2014).

Entre os agricultores que não eram tradicionais na cultura local foram escolhidos mais dois grandes grupos de agricultores familiares presentes no município: os proprietários e os arrendatários. Apesar de sua origem cultural distinta, estes dois grupos mostram uma base anterior comum, que é a forma intensiva de produção nos moldes da Revolução Verde, que foi trazida a Ubatuba pelos primeiros japoneses que ali chegaram nos anos 50. A maioria deles reconhecia os problemas de saúde associados ao excesso de uso de produtos químicos nas lavouras e queriam mudar, ou já estavam em processo de transição, para práticas agroecológicas (MARCHIORI et al., 2014). Durante este projeto foi desenvolvida a técnica social da "Estufa Ubatubana" - técnica atualmente amplamente difusa nas propriedades agrícolas de Ubatuba. A estufa é uma forma de cultivo protegido com cobertura plástica de baixo custo e foi desenvolvida para viabilizar a produção de hortaliças nas condições climáticas do litoral norte de São Paulo. (ROJO VEGA et al., 2013).

A partir do projeto de extensão executado pela UPD de UBATUBA e com financiamento da PETROBRAS, o Instituto de Permeacultura da Mata Atlântica (IPEMA) - uma ONG de atuação local no município -, começou a desenvolver o Projeto Juçara, de longa duração, com a comunidade de Ubatumirim, utilizando o manejo e produção para comercialização da polpa visando a preservação da palmeira juçara. Por meio deste projeto e com o apoio da Secretaria Municipal de Agricultura 
(SMAPA), cinco membros da Associação de Bananicultores de Ubatumirim constituíram em 2009 o primeiro OCS da região. Um dos resultados do Projeto Juçara foi a inserção de alguns produtores no circuito do PNAE no período de 2012 até 2015, quando em função de conflitos internos a organização parou de funcionar de forma coletiva5.

Com a intenção de expandir a base de produtores agroecológicos, facilitar o escoamento da produção e construir laços entre produtores e consumidores conscientes da cidade, os mesmos atores institucionais que estavam por trás do Projeto de Propriedades de Referência, com alguns produtores que passaram pelo processo da transição agroecológica, formaram em 2013 a versão embrionária da Rede Agroecológica Caiçara - atualmente, o principal mercado de agroecológicos do município.

A Rede Agroecológica Caiçara (Rede) é resultado da interação de confiança entre produtores e consumidores no município de Ubatuba-SP e durante seis anos se consolidou como coletivo de produção e consumo responsável, fomentando a venda direta da produção agroecológica e artesanal na região. Conforme material de divulgação da Rede, o preço dos produtos busca o equilíbrio para que seja justo para ambos o produtor e consumidor. Esse tipo de relação direta permite o uso mais racional dos recursos, resultado de menores gastos com transporte e armazenamento, redução de intermediários na distribuição, incentivando a produção de base ecológica, uma vez que possibilita que os produtores recebam mais pelos produtos. Desse modo, os preços não sofrem regulação interna e é sugerido que não superem os preços praticados no mercado convencional. A Rede conta com um Regimento Interno, mas prioriza o diálogo e consenso. Conta também com um Protocolo de Adesão que contém os valores norteadores do trabalho e convivência coletiva - e com um Cronograma de Trabalho Voluntário onde ficam definidas as atribuições e as equipes de voluntários durante a comercialização semanal. Os produtores de hortaliças tem que ser oficialmente certificados (por auditoria ou OCS).

Desde a sua concepção a Rede cresceu e incorporou, além de produtores agroecológicos e consumidores conscientes, artesãos locais e de comunidades tradicionais, gerando tensão no modelo de governança. Durante entrevista com uma das fundadoras da Rede esta tensão fica evidente:

o medo era descaracterizar o que tínhamos montado. Não é fácil assim, convidar todo mundo e tudo fica bem. As pessoas vêm com conceitos diferentes. $O$ tempo dos agricultores é diferente. $O$ agricultor familiar tem seus objetivos. $O$ artesão tem outros. E o "bicho grilo" que quer viver sem luz e plantar e viver daquilo tem outros. Concertar isso é o nosso maior desafio hoje. Mas valeu a pena. Acho que a Rede ficou mais forte assim. Aumentou as vendas. Na verdade, o valor das vendas com artesanato é maior do que das verduras (Entrevista, 08/2019).

\footnotetext{
5 Três causas contribuíram para a desarticulação dos produtores com o PNAE. O primeiro era de natureza interna, em função da frágil gestão da unidade comunitária de beneficiamento da polpa de Juçara. De fato, o IPEMA priorizou o lado técnico com a comunidade sem incorporar processos formativos da gestão social. O segundo, também de natureza interna, está associado à falta de transparência na Associação de Bananicultores de Ubatumirim ( $A B U)$, que gerenciava a entrega dos produtos. O terceiro ponto, de natureza externa, foi a postura agressiva de outros produtores locais que buscaram capturar o mercado. (Informações colhidas em entrevista com extensionista rural do IPEMA, setembro 2019).
} 
Todo o formato da Rede é participativo, uma vez que produtores e consumidores se organizam em equipes de voluntários. Inicialmente, para viabilizar a comercialização, os membros se organizavam da seguinte forma: semanalmente era disponibilizada a lista de fornecedores e seus produtos no sistema "Cirandas". Acessando a plataforma, o consumidor escolhia os produtos que desejava adquirir. Antes da feira "abrir as portas" os voluntários designados montavam as cestas. Às quartas-feiras os produtores e consumidores se encontravam para entrega dos produtos. Hoje, esse sistema não está mais em funcionamento, toda a estrutura se resume a uma feira.

Atualmente estão cadastrados no sistema 50 fornecedores, entre agricultores familiares - que tradicionalmente produzem sem o uso de produtos sintéticos agricultores em transição agroecológica, produtores que cultivam em seus quintais e tem na Rede uma oportunidade de escoar o excedente de sua produção, além de produtores de artigos naturais de higiene pessoal, saúde e limpeza. Entre os parceiros consumidores há os moradores de Ubatuba, veranistas, donos de estabelecimentos de comércio de alimentos, pequenos restaurantes, profissionais da Prefeitura, do Estado, membros de ONGs. O Facebook e Instagram da Rede são as principais ferramentas de ação política e de integração de pautas para além do setor rural ou agrícola. Esporadicamente os representantes da Rede também participam das reuniões da Comissão Estadual de Produção Orgânica (CPOrg/SP), onde são discutidos assuntos estratégicos sobre o crescimento do setor no Estado.

Em sua tentativa mais recente de diversificar os canais de comercialização a Rede criou em setembro de 2015 o grupo de Whatsapp "Feirinha da Rede" para receber pedidos de produtos, substituindo o uso do sistema Ciranda. O grupo virtual atualmente tem 140 participantes entre consumidores e produtores. Ainda, a Rede conta com vendas para festas da cidade e para alguns restaurantes localizados no município. Além de se organizar para comercialização dos produtos locais, parte dos produtores e consumidores da Rede constituem grupos descentralizados de compras coletivas, adquirindo os produtos orgânicos da Cooperativa de Trabalhadores Assentados na Região de Porto Alegre (COOTAP) e outros produtos orgânicos e agroecológicos. Os grupos compram regularmente arroz, café, castanhas, óleos vegetais, farinhas, tahine orgânicos para consumo pessoal e como forma de baratear custos de insumos na produção de alimentos de valor agregado.

O surgimento do movimento de transição agroecológica em Cunha remonta ao Projeto "Viver na Mata Atlântica", financiado pela PDA/MMA e executado de 2006 a 2010 pela ONG Serra Acima. Este foi também o primeiro projeto da Serra Acima na área de agroecologia, pois antes atuavam desde 1999 com o atendimento a crianças e adolescentes em situação de vulnerabilidade social. A associação desenvolveu o projeto em parceria com as duas unidades de conservação no município (Parque Estadual Serra do Mar e o Parque Serra da Bocaina), a Prefeitura de Cunha, a CATI e quatro associações de bairros rurais. O projeto visava armar modelos demonstrativos de recuperação ecológica de matas ciliares e nascentes aliada ao fortalecimento da agricultura familiar e da agroecologia na região das Nascentes da Bacia Hidrográfica do Rio Paraíba do Sul.

Foi por meio deste projeto que as primeiras capacitações de produção agroecológica foram ministradas com os produtores rurais. Contudo o projeto não 
tinha o objetivo de construir novos mercados. Esta lacuna seria suprida pela Serra Acima em 2008, com o Projeto "Formação e desenvolvimento de cadeias produtivas", financiado pela BVS\&A ${ }^{6}$. No âmbito deste projeto foram realizados cursos de capacitação em comercialização e um diagnóstico das cadeias produtivas do leite 7 , hortaliças e pinhão, escolhendo as hortaliças como cadeia prioritária para os produtos agroecológicos. A entrada no PNAE era facilitada por uma ampla coalizão de instituições locais incluindo os produtores agroecológicos, a CATI, a Secretaria da Educação, a administração das escolas e a nutricionista do programa. Este arranjo durou até a virada da gestão em 2016 quando as compras caíram drasticamente. As coalizões sociais construídas na escala municipal, nos espaços institucionais de participação social, também serviram para definição dos cardápios da alimentação ofertada às escolas e sua adaptação aos cultivos e ciclos locais.

Para atender as necessidades do PNAE no município os agricultores familiares formaram em 2009 o Grupo de Agricultores Familiares Agroecológicos de Cunha (GAFAC). Em 2011 o GAFAC constituiu a Feira Agroecológica de Cunha. A Feira tem regimento interno que regula seu funcionamento. As regras de entrada $e$ responsabilidades dos feirantes representa compromisso explícito com a produção agroecológica dos alimentos comercializados. Em 2016 o GAFAC foi formalizado como Associação de Produtores Agroecológicos de Cunha (APAC). Atualmente, cerca de 30 pessoas e 15 famílias estão associadas à APAC. Destes, 25 obtiveram a Declaração de Aptidão (DAP) entre 2014 e 2015 junto ao Ministério do Desenvolvimento Agrário (MDA).

De 2009 até 2011 foram realizados três seminários municipais sobre a agroecologia com a participação dos agricultores familiares, professores das redes públicas de ensino, consumidores da feira agroecológica e funcionários públicos. Em 2010, durante o segundo seminário também foi lançado o $1^{\circ}$ Seminário de Troca de Sementes Crioulas reunindo 100 participantes da região, incluindo produtores de São Luís do Paraitinga e Ubatuba. Em 2011 o seminário contou com a participação da Rede Ecovida e do MAPA, por meio da Superintendência Regional do Estado de São Paulo, que apresentou a legislação referente aos OCS. Como resultado deste seminário seis produtores afiliados ao GAFAC constituíram em 2011 a OCS Agricultores Familiares de Cunha. Atualmente estas seis famílias comercializam produtos $100 \%$ agroecológicos via PNAE.

Conforme os registros da Serra Acima, a transição agroecológica teve um impacto positivo na rentabilidade dos agricultores familiares (FRESCHI et al., 2015). No período de 2009 a 2011 o crescimento da renda monetária média das famílias que participaram da OCS Agricultores Familiares Agroecológicos teve o crescimento da ordem de $46,8 \%^{8}$ chegando a $\mathrm{R} \$ 907 /$ mês, somando todas as fontes de renda

\footnotetext{
${ }^{6}$ Os cursos de longa duração aplicaram metodologias pedagógicas de alternância, misturando teoria e prática. Para a formação mercadológica os participantes do processo de formação foram expostos a aprendizagem-entrepares, visitando fazendas certificadas por auditoria (em Guaratinguetá e Cunha) especializadas em produção de hortaliças. Também foi feita uma excursão de 5 dias com 16 participantes para conhecer as experiências da Rede Ecovida-PR.

7 A cadeia do leite em Cunha também apresentou alto potencial, porém foi descartada em função da forte centralização na Cooperativa de Laticínios em Guaratinguetá, voltada a produção convencional do leite e do baixo potencial de capitalização dos produtores.

8 Tomando como base o faturamento médio de uma família que vendia na porteira, na Feira e no PNAE, a renda em 2011 era de $\mathrm{R} \$ 907 /$ mês, o que equivalia a uma remuneração diária de $\mathrm{R} \$ 41$, enquanto o trabalhador rural avulso naquele ano recebia em média $\mathrm{R} \$ 27 /$ dia (FRESCHI et al., 2015).
} 
(porteira, feira e PNAE). Até 2015 a renda por família, derivada só da feira agroecológica, ultrapassava os R\$950/mês - um aumento de quase $25 \%$ comparado com o ano de 2013.

Contudo, as primeiras grandes tensões da transição agroecológica no município vieram em 2016, entre a APAC e o Grupo BioCunha Alimentos Agroecológicos - um novo grupo formado por oito famílias de agricultores. Os conflitos surgiram em função da disputa por mercado, se acirraram a partir de antigas rixas familiares que, em grande parte, foram alimentadas pela atuação dual e antagônica da extensão rural do terceiro setor e das estruturas públicas locais. A formação do grupo BioCunha teve uma trajetória marcada pela presença institucional da CATI e pelo forte engajamento da sua gestão local e do quadro de extensionistas rurais. Sua gênese está ligada à formação da Associação de Apicultores de Cunha (APICUNHA), que em 2013 recebeu apoio do Programa Estadual Microbacias II Acesso ao Mercado. Muitos dos membros da Associação foram treinados em técnicas de agroecológia. Durante os cursos os agricultores definiram a construção de uma feira agroecológica para comercializar as hortaliças, frutas, mel e outros produtos. Desde 2018 a BioCunha conta com a certificação OCS e atua em diversas frentes de mercado. Dentre estes destacam-se: a Feira semanal na praça, o DiskRoça que faz entregas de cestas de alimentos para a cidade e região, e a Comunidade que Sustenta a Agricultura (CSA).

No começo de 2019 a BioCunha elaborou seu regimento interno definindo as regras de entrada ${ }^{9}$ e gestão dos mercados agroecológicos. O regimento incorpora em suas cláusulas os procedimentos exigidos pelo MAPA para garantir a conformidade com a Lei Nacional de Agricultura Orgânica 10.831/2003 e a Instrução Normativa 64 que regulamenta as formas de produção orgânica. O Regimento ainda define as regras de gestão compartilhada de cada canal de comercialização. A feira do BioCunha conta com regras próprias de funcionamento. Todos os feirantes têm a responsabilidade de registrar as vendas e práticas a preços justos combinados em reuniões prévias. O DiskRoça foi a segunda evolução inovadora do grupo e tem como objetivo facilitar a entrega dos produtos nas pousadas, demonstrando integração do BioCunha com outros circuitos comerciais no município. O DiskRoça ainda incorpora um rateio de valores a ser repassado para os agricultores, os entregadores e a equipe de voluntários responsáveis pela embalagem. O terceiro e último sistema, CSA, é o mais complexo e demonstra amadurecimento de gestão do grupo ${ }^{10}$, bem como aproximação entre produtores e consumidores. Cada produtor pode ter até seis cotistas (consumidores do município) por um prazo de 2 meses. Durante este período o consumidor se compromete a adquirir com antecedência a produção do agricultor. O valor pago pelo cotista é $R \$ 85 /$ mês e o produtor se compromete com a entrega de oito produtos por semana. Atualmente há 11 cotistas no sistema e oito produtores. $O$

\footnotetext{
9 No período de 6 meses o interessado deverá participar de um mínimo de 3 reuniões mensais e 10 feiras. O novo membro precisa comprovar conformidade com a legislação vigente referente a produção agroecológica. Agricultores não familiares podem participar, porém, em proporção de até $20 \%$ do número total de agricultores familiares, sem direito a voto em decisões Estatutárias ou de Normas da Associação.

${ }^{10} \mathrm{Em} 2018$ o grupo enfrentou dificuldades para operar os serviços do DiskRoça e o CSA, em função do alto custo do frete. Assim organizaram uma campanha de crowd-funding e arrecadaram $\mathrm{R} \$ 8.000$ para compra de veículo usado financiado. Esse carro foi adquirido em 2019 e permite ampliar a entrega de cestas e o CSA. Além disso, o carro é usado para realizar visitas às escolas da região para facilitar troca de conhecimentos entre agricultores e alunos ampliando a base de apoio das coalizões sociais. Ver: https://benfeitoria.com/biocunha
} 
padrão de qualidade, volume e prazos de entrega são combinados entre os produtores e os respectivos cotistas. Porém, o Regimento Interno do BioCunha define algumas diretrizes básicas para manter o padrão de qualidade. Para além do CSA, o DiskRoça e a Feira Agroecológica geram renda adicional no valor médio por família de $\mathrm{R} \$ 400-\mathrm{R} \$ 450,00 /$ mês cada.

Os municípios de Ubatuba e Cunha estão inseridos na transição agroecológica desde os meados dos anos 2000. As diversas inovações tecnológicas, organizacionais e mercadológicas aplicadas na transição agroecológica nestes dois municípios tem pontos em comum, a saber: a) a presença da extensão rural (institucional e do terceiro setor) foi fundamental para construir os conhecimentos técnicos e organizacionais dos atores engajados; b) os produtores estão organizados em múltiplas formas de controle social, em conformidade com a regulamentação vigente; e c) há uma variedade dinâmica de mercados em construção, desde as feiras, CSA, sistema de pronta entrega, vendas diretas e cestas, integradas com ferramentas digitais, permitindo a aproximação das experiências a um mercado cada vez maior de consumidores.

A partir da análise empreendida é possível atestar que há potencial escalar significativo, mas as experiências seguem em estágio embrionário.

Em síntese, três características específicas da transição agroecológica em Ubatuba podem se ressaltadas.

Em primeiro lugar, a experiência local comprova a constatação de Fligstein e Dauter (2007) sobre a importância central do Estado em garantir um ambiente estável para a construção social e consolidação de novos mercados. A articulação entre a extensão rural e a pesquisa, ambas financiadas e coordenadas por agências do Estado realçam esta centralidade. No âmbito institucional, a priorização do fortalecimento da cadeia produtiva de olericultura orgânica como projeto estruturante da APTA Polo Regional Vale do Paraíba - Unidade de Pesquisa de Desenvolvimento de Ubatuba deriva da integração desta agência com a Prefeitura Municipal de Ubatuba, participação no Conselho Municipal de Desenvolvimento Rural e Pesqueiro de Ubatuba e da proximidade dos técnicos da sede regional com a iniciativa da Rede Agroecológica Caiçara. Ainda, os agentes extensionistas da CATI e pesquisadores da APTA do município participam como observadores das reuniões do CPorg do Estado de São Paulo, facilitando a aproximação da extensão rural com a Superintendência Estadual do MAPA - órgão fiscalizador dos produtores certificados orgânicos. Esta aproximação é fundamental para poder garantir a conformidade dos produtores certificados perante a legislação nacional.

A segunda constatação que podemos inferir é que a formação e atuação da Rede está focada, na escala local, com forte enraizamento territorial, seja do ponto de vista da inclusão produtiva das comunidades tradicionais, como em relação ao consumo inclusivo e acessível, praticando uma política de preços justos. É importante mencionar que as metodologias pedagógicas dos projetos de extensão se espelharam em abordagens construtivistas, da aprendizagem entre pares e da pesquisa-ação como forma de juntar conhecimentos técnicos com saberes tradicionais. Contudo, mesmo tendo contato direto com as comunidades tradicionais, a Rede, como unidade coletiva, não tem como pauta oficial a luta por direitos fundiários, tema sensível local com impactos sobre as condições de produção, e também não atua diretamente nas discussões sobre a segurança 
alimentar nos espaços institucionais de participação social. Embora a Rede tenha produtores de origem de comunidades tradicionais, ela não tem assento no Conselho do Grupo Gestor do Parque e também não está articulada com o Fórum de Comunidades Tradicionais de Paraty e Ubatuba. Contudo, a Rede tem assento no CMDRP e contribui na construção da política setorial do município. A única articulação regional da Rede está vinculada à Câmera Técnica de Agroecologia do Comitê de Bacias do Litoral Norte (CTAgroSAF).

A terceira e última constatação se refere ao distanciamento da Rede dos circuitos de compras públicas. Mesmo sendo criada de forma híbrida, com a forte participação dos extensionistas estatais, a Rede não atua nesta frente e isso pode ser explicado em função de dois fatores. De um lado, a ênfase da Rede está na construção de relações diferenciadas entre o consumidor e o produtor, e a atual estrutura institucional das compras públicas não se configura como espaço aberto para este tipo de abordagem. Por outro lado, a estrutura institucional local do PNAE está em processo de desestruturação em função das mudanças políticas na escala nacional. ${ }^{11}$

Já o movimento de transição agroecológica em Cunha pode ser resumido a três fases: a) de 2006 a 2009: fase de formação social e capacitação técnica; b) 2009 - 2010: fase da inserção mercadológica celebrada com a entrada no circuito de compras públicas via PNAE; e 3) 2011 - atual: fase de diversificação e fragmentação do movimento.

De fato, a transição ecológica em Cunha teve um forte dinamismo durante os primeiros cinco anos, mas atualmente encontra-se estagnada. Dois fatores contribuem para isto. O primeiro, de corte organizacional, é a falta de interlocução entre as duas organizações de controle social e os conflitos que derivaram deste descompasso. A ausência de uma coalizão social (neste caso entre os atores do mesmo setor) entre estes atores parece estar enfraquecendo a transição como todo, pois onde poderia haver sinergias e expansão de redes ocorrem disputas e dissonâncias. O segundo fator, de cunho institucional, está associado à impermeabilidade das agendas em instâncias supramunicipais. Enquanto na escala local a CATI de Cunha está engajada na construção social do mercado local de hortaliças agroecológicas, a gerência regional parece ter como ação prioritária o aumento de produtividade da cadeia do leite convencional.

${ }^{11}$ O principal espaço de articulação desta política é o Conselho da Merenda Escolar e o Conselho de Segurança Alimentar e Conservação. A Rede não conseguiu estabelecer laços permanentes com nenhum dos dois conselhos. 
Figura 4: Escala da transição agroecológica nos municípios de Ubatuba e Cunha - SP

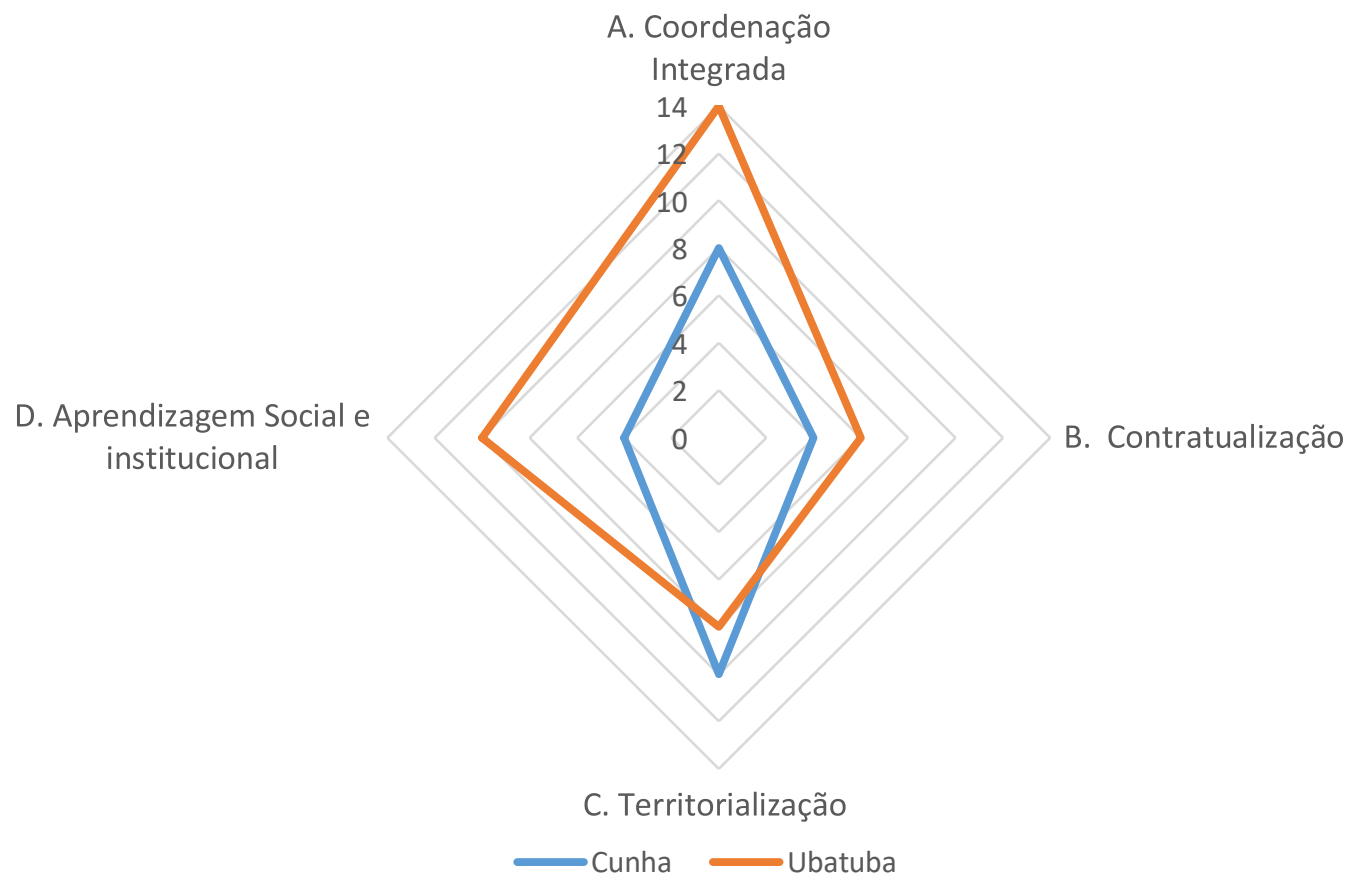

Em síntese podemos observar que as duas experiências de construção social do mercado de agroecológicos no município de Cunha apresentam diferentes graus de habilidades sociais construídas durante o processo de formação. A cooperação local continua fragmentada, inclusive dentro da mesma categoria de produtores. De um lado, a experiência de BioCunha dirigida até muito recentemente pela extensão rural da CATI depende da articulação institucional com outros setores da economia local. É preciso registar que há indícios de que a BioCunha esteja tateando um processo de ampliação de suas relações que pode resultar em potencial formação de uma coalizão mais expressiva, o que se observa em indicativos como o serviço de entrega do DiskRoça e a constituição do CSA. Contudo há uma ausência de articulação, engajamento e incidência pública com as estruturas formais de participação social e com as institucionalidades locais. Este é o ponto que mais diferencia as duas experiências em Cunha. Em diversas ocasiões e entrevistas com os atores locais discutiu-se a dificuldade de interlocução com a Prefeitura e com o diretório Regional da Guaratinguetá da CATI. A desarticulação do Conselho Municipal, a priorização da extensão rural na ótica da agricultura convencional para a cadeia do leite e, consequentemente, a falta de acompanhamento mais sistemático pela CATI dos produtores agroecológicos de hortaliças, são aspectos que figuram como os principais empecilhos na construção de coalizões sociais mais amplas em prol do fortalecimento da transição agroecológica no município.

Enquanto a OCS BioCunha começa com o apoio institucional e avança para a tentativa de buscar consolidar o mercado de agroecológicos, a experiência da OCS Agricultores Familiares Agroecológicos começa com apoio do terceiro setor e, posteriormente, é orientada para escoamento no canal institucional do PNAE. Se de um lado isso demonstra a habilidade dos interlocutores em tentar ampliar seu rol de 
relações em direção a coalizões mais amplas, vemos que, a partir dos dados apresentados acima, tais estratégias são ainda muito instáveis.

\section{Conclusão}

A matriz analítica aplicada neste trabalho permite observar como a transição agroecológica está se estruturando, quais espaços propícios têm sido acessados na tentativa de armar coalizões sociais que possam ampliar a geração de conhecimentos e inovações, permitindo enfim maior dinamismo e escala. No caso de Ubatuba, a transição ganha tração por meio das coalizões formadas no cerne da Rede Agroecológica Caiçara, e por meio da articulação com espaços institucionais na escala local e territorial. Contudo, seu alcance continua limitado em termos de incidência pública e capacidade de orientar o rumo do desenvolvimento local. No caso de Cunha, há capacidade local de construir coalizões sociais além do segmento original, procurando vincular a transição agroecológica ao setor dinâmico do turismo rural, em franca expansão. Também foi possível observar habilidades sociais aplicadas no acesso ao mercado das compras institucionais. Por outro lado, ficou clara também a dificuldade de ampliar estas coalizões sociais de maneira a fortalecer o setor perante as instâncias públicas, cruciais para a escala de uma transição de maior incidência. Como se vê, portanto, duas situações que, por caminhos distintos, evidenciam como as relações sociais enraizadas nos territórios se traduzem em potencialidades, mas também em limites para uma transição mais expressiva.

A ênfase em aplicar uma abordagem relacional, como se propôs aqui, é uma tentativa de mostrar um conjunto de interdependências que são fundamentais para pensar a coprodução do território e de certas práticas em seu interior, caso das tentativas de transição agroecológica. Isto permitiu ir além da dimensão setorial, da armadilha escalar e da dualidade nicho-regime dos processos de inovação, aspectos muito presentes em parte significativa da literatura sobre estes processos de transição. Evidenciar características do tecido social dos territórios e como eles se traduzem em habilidades sociais dos agentes para ampliar coalizões e formar arenas reflexivas de governança permite entender porque, mesmo em um contexto espacial e institucional favorável, próximo a mercados e centros urbanos e com uma certa densidade institucional favorável, a transição agroecológica pode ficar presa a armadilhas escalares de um localismo restritivo (MARSDEN; SONNINO, 2006), e defensivo (HINRICH, 2003).

\section{REFERÊNCIAS}

BRASIL. Instituto Brasileiro de Geografia e Estatística. Síntese de Indicadores Sociais. Uma análise das condições de vida da população brasileira, 2018. Disponível em: https://biblioteca.ibge.gov.br/visualizacao/livros/liv101629.pdf. Acesso em: 10 maio 2019.

. Instituto Brasileiro de Geografia e Estatística. Censo agropecuário 2017. Disponível em: https://biblioteca.ibge.gov.br/visualizacao/livros/liv101629.pdf. Acesso em: 10 maio 2019. 
BROWN, B. e PURCEL, M. Avoiding the Local Trap Scale and Food Systems in Planning Research. Journal of Planning Education and Research. Vol. 26, pp. 195207, 2004 .

BRUNORI, G.; ROSSI, A.; MALANDRIN, V. Co-producing transition: innovation processes in farms adhering to solidarity-based purchase groups (GAS) in Tuscany, Italy. International Journal of Sociology of Agriculture and Food. Vol. 18(1): 28-53, 2011.

BUAINAIN, A.M. Agricultura familiar, agroecologica e desenvolvimento sustentável: questões para debate. Brasília: IICA, 2006 136p.

COMITÊ DE BACIAS HIDROGRÁFICAS DO LITORAL NORTE. CBH-LN. Relatório anual da situação dos recursos hídricos do Litoral Norte, 2017, 211p.

EMBRAPA. Marco referencial em agroecologia. Brasília: DF. EMBRAPA: Informação Tecnológica, 2006, 72p.

ESTADO DE SÃO PAULO. Empresa Paulista de Planejamento Metropolitano, EMPLASA. Informações sobre a Região Metropolitana do Vale do Paraíba e Litoral Norte. Disponível em: https://www.emplasa.sp.gov.br/RMVPLN. Acesso em: 10 maio 2019.

. Fundação Sistema Estadual de Análise de Dados - SEADE. Informações dos Municípios: Cunha, São Luís do Paraitinga e Ubatuba. Indicadores Economicos e Demográficos. 1980-2018 www.perfil.seade.gov.b. Acesso em: 10 maio 2019.

. Secretaria da Agricultura e Abastecimento. LUPA. Levantamento Censitário das Unidades de Produção agropecuária do estado de São Paulo, 2007-2008. Disponível em: http://www.cati.sp.gov.br/projetolupa/dadosmunicipais.php. Acesso em: 10/05/2019

FAVARETO, A. Paradigmas do desenvolvimento rural em questão. São Paulo: Iglu/Fapesp. 2007.

FAVARETO, A. et al. Territórios importam - bases conceituais para uma abordagem relacional do desenvolvimento das regiões rurais ou interioranas no Brasil. ReGis. Brasília, v. 1, p. 13-33, 2015.

FLIGSTEIN, N. AND DAUTER, L. The Sociology of Markets. Annual Review of Sociology 33: 105-28, 2007.

GEELS, F. W. Technological transitions as evolutionary reconfiguration processes: a multilevel perspectives and a case-study. Research Policy, Amsterdam, n.31, p. 1257$1274,2002$. 
GLIESSMAN, S.R. Agroecology: Ecology of sustainable food systems. Boca Raton, FL: CRC/Taylor \& Francis, 2007, 408p.

HINRICHS, C.C. The practice and politics of food system localization. Journal of Rural Studies. 19(1): 33-45, 2003.

HORLINGS, L.G.; MARSDEN, TK. Towards the real green revolution? Exploring the conceptual dimensions of a new ecological modernization of agriculture that could feed the world. Global Environmental Change. Vol. 21: 441-452, 2011.

KOOIMAN, J. Governing as Governance. London: Sage, 2013, 249p.

MARCHIORI, A. C. C. ; VEGA, S. M. R. ; VIEGAS, I.F.P. ; TURCO, P. H. N. ; OTANI, M. . Elaboração do Plano de Etnodesenvolvimento Sustentável de Duas Comunidades Tradicionais em Ubatuba, Litoral Norte de São Paulo - Diagnóstico Lento Participativo. $52^{\circ}$ Congresso da Sociedade Brasileira de Economia, Administração e Sociologia Rural., 2014, Goiânia. 2014.

MARSDEN, T. From post-protectionism to reflexive governance: contested transitions in securing more sustainable food futures. Journal of Rural Studies 29 pp. 123-134, 2013.

MARSDEN, T. Exploring the Rural Eco-Economy: Beyond Neoliberalism. Sociologia Ruralis, Vol 56, Number 4, October. 598-615, 2016.

MARSDEN, T.; SONNINO, R. Rural development and the regional state: denying multifunctional agriculture in the UK. Journal of Rural Studies. Vol. 24: 422-431, 2008.

NIEDERLE, P.A. Transições no sistema agroalimentar. XI Congresso da Sociedade Brasileria de Sistemas de Produção. Abordagem sistêmica e sustentabilidade: produção agropecuária, consumo e saúde. 06 a 08 de julho, Universidade Federal de Pelotas, 2016

NIEDERLE, P.A. Afinal, que Inclusão produtiva? A contribuição dos novos mercados alimentares. Em: Delgado, Guilherme Costa. Bergamasco, Sonia Maria Pessoa Pereira (orgs.) Agricultura familiar brasileira: desafios e perspectivas de futuro. Brasília: Ministério do Desenvolvimento Agrário, 2017.

PREFEITURA MUNICIPAL DE UBATUBA. Plano Diretor Municipal Participativo. 2006. https://www.ubatuba.sp.gov.br/planodiretor. Acesso em: 5 maio 2019.

RENTING, H. ET AL. Exploring multifunctional agriculture. A review of conceptual approaches and prospects for an integrative transitional framework. Journal of Environmental Management. Vol. 90: 113-123, 2012. 
ROEP, D.; WISKERKE, J.S.C. Reflecting on novelty production and Niche Management in Agriculture. In: Seeds of Transition. J.S.C. Wiskerke nd J.D va der Ploeg (eds.), 2004, 356p.

ROJO VEGA, S. M.; MARCHIORI, A. C. C.; CASTRO, C. E. F.; VIEGAS, I.F.P.; FIRETTI, R. Redes de propriedades de referência em sistemas de produção agroecológicos em Ubatuba, SP. $51^{\circ}$ CONGRESSO DA SOBER. Anais..., Belém, PA, 2013.

SCHMITT, Cláudia. Transição agroecológica e desenvolvimento rural: um olhar a partir da experiência brasileira. In: SAUER, S. e BALESTRO, M. (Org.). Agroecologia e os desafios da transição agroecológica. São Paulo: Expressão Popular, 2009. p. 177204.

SONNINO, R.; MARSDEN, T. Beyond the divide: rethinking relationships between alternative and conventional food networks in Europe. Journal of Economic Geography. Vol. 6: 181-199, 2006.

SWYNGEDOUW, E. Scaled geographies: nature, place and the politics of scale. In E. Sheppard \& R. McMaster (Eds.). Scale and Geographic Inquiry. Oxford: Blackwell, 129-153, 2004.

M. John Wojciechowski. Doutor em Planejamento e Gestão do Território. Universidade Federal do ABC. Matias.john.w@gmail.com

Arilson Favareto. Professor Adjunto de Análise Econômica para Ciência e Tecnologia na Universidade Federal do ABC do Programa Planejamento e Gestão do Território. arilson.favareto@ufabc.edu.br

Silvia Moreira Rojo Vega. Chefe da Seção Técnica da Unidade de Pesquisa e Desenvolvimento da Agência Paulista de Tecnologia dos Agronegócios - Unidade Ubatuba.silviamoreira@apta.sp.gov.br

Isabel Fernandes Pinto Viegas. Pesquisador científico nível IV da Agência Paulista de Tecnologia dos Agronegócios. Agência Paulista de Tecnologia dos Agronegócios - Ubatuba - São Paulo - Brasil. isabelviegas@apta.sp.gov.br

Como citar: WOJCIECHOWSKI, Maciej John et al. Uma leitura territorial e escalar dos processos inovadores da transição agroecológica em dois municípios do Vale do Paraíba e do Litoral Norte de São Paulo, Brasil. Redes (St. Cruz Sul, Online), Santa Cruz do Sul, v. 25, n. 1, jan. 2020. ISSN 1982-6745. DOI: https://doi.org/10.17058/redes.v25i1.14639. 
Uma leitura territorial e escalar dos processos inovadores da transição agroecológica em dois municípios do Vale do Paraíba e do Litoral Norte de São Paulo, Brasil

\section{CONTRIBUIÇÃO DE CADA AUTOR}

Fundamentação teórico-conceitual e problematização: M. J. Wojciechowski Pesquisa de dados e análise estatística: M. J. Wojciechowski, Silvia Vega e Isabel Veiga. Elaboração de figuras e tabelas: $M$. J. Wojciechowski Fotos: não se aplica

Elaboração e redação do texto: M. J. Wojciechowski, Arilson Favareto, Silvia Veja, Isabel Veiga Seleção das referências bibliográficas: $M$. J. Wojciechowski 